\title{
INCOME CONTINGENT REPAYMENTS - HOW CAN WE GET INTO A DEBT TRAP?
}

\section{Berlinger, E., Walter, G.}

Income contingent schemes have been widely used in student lending in the last few decades. Recently, in the aftermath of the crisis of 2007-2008, several authors argued that income contingent loans have much better risk profiles than traditional fixed loans, and they proposed to extend their scope to other areas of retail lending, too. Hence, understanding this scheme can be relevant from the point of view of both human resource management and financial engineering. In this paper we analyzed the unusual characteristics of income contingent repayments, and derived closed formulas for stability, success and shape. We concluded that humped debt paths can be frightening; however, if the growth rate of the debt is lower than the growth rate of the income, then it is not a debt trap, but a natural consequence of this patient and flexible scheme, which requires new methods of communication, risk management, financing and administration.

Keywords: income contingent repayment; student loan scheme; retail lending; debt trap JEL classification: 122, G21, G01

\section{Introduction}

In practice, the term 'income contingent (IC) loan' covers several repayment systems. All loans which are dependent on some individual or aggregate income category under a defined algorithm can be considered as income contingent. In this paper we investigate "pure" IC schemes where the actual repayment is a fixed proportion of the actual individual income. In such a scheme, maturity is not predefined, but it depends on the future incomes. The more someone earns, the higher the repayment is, hence the earlier he/she can fully repay the debt. This scheme has two major advantages relative to traditional fixed loans, (Barr, 1998; Stiglitz et al. 2014; Berlinger \& Walter, 2015):

- Patience: Loans have longer maturity and much longer duration.

- Flexibility: The repayment obligation automatically adjusts to the actual income; hence temporary low income does not lead to default. On the other hand, high income periods speed up the repayment; hence the lender's exposure is effectively reduced.

The disadvantages of IC schemes are related to the administrative burden of permanent income checking and the incentive problems (borrowers may be tempted to work less or hide their income). In this paper we set aside these issues and focus only on the basic characteristics of IC schemes, with a special emphasis on the conditions of successful repayment and the shape of the debt paths.

Income contingent loan schemes have practical relevance for at least three reasons. First of all, human resource managers must deal with an increasing number of graduates having income contingent repayment obligations due to their student loan, as several income contingent student loan systems were introduced during the last decades throughout the world, in the EU and also in CEE. When setting up a carrier plan and 
designing a corresponding compensation package, student loans should also be taken into account. We also note that in most of the cases, the employer can directly repay the student loan of his employee in a rather cost effective way. Secondly, IC loans can be extended to other areas of retail lending, as well. For example, the continuous deterioration of some retail portfolios and the failure in handling them with usual work-out banking techniques led to the consideration of new solutions; and the introduction of an income contingent repayment scheme can be one of these. Therefore, a possible application to non-performing mortgage portfolios in the retail sector is under discussion in some countries, for example in Hungary, see (Berlinger \& Walter, 2015). Finally, our results can easily be generalized to all equity-like financing - e.g. Islamic banking, private equity funds - by a proper redefinition of the model variables.

Our research questions are as follows: Under what conditions will an IC loan be fully repaid over a lifetime (until retirement)? What is the expected maturity of an IC loan under different conditions? When can a borrower get into a debt trap? How can individual debts evolve over time?

The paper is structured as follows: in Section 2 we briefly overview the relevant literature; in Section 3 we present the model, in Section 4 we derive the results, while in Section 5 we discuss conclusions and practical implications.

\section{Literature Review}

The literature of IC loans covers all practically relevant issues mentioned above (student lending, possible extensions to a wide range of retail lending, equity-like financing in general).

The idea of income contingent student loans was raised by Friedman (1962). He proposed that highly risky human investments (long maturity, no physical collateral, non-hedgeable risks and uncertainties) should be financed from equity-like capital, where the repayment is not fixed but depends on the return of the investment, i.e. the graduate's income. He described a model which was closer to a graduate tax system than to income contingent loans. Based on the experiences of the first IC student loan systems of Australia and New Zealand, Harding (1995) worked out a thorough microsimulation and analyzed the repayment patterns of the borrowers. Chapman (1997) and Barr (1998) further developed the idea of IC loans from a theoretical point of view. Barr (2001) argued for involving private funds into higher education, analyzed the failure of financial markets to provide student loans, and on this ground, he advocated the introduction of IC schemes as an ideal policy tool. He described the further characteristics of a well-designed student loan, as well: large enough to cover tuition fees and living costs; universally accessible, self-sustaining and capable of being privately financed. Other authors discussed the role of IC loans in higher education and the worldwide experiences of student lending, for example Palacios (2003), Shen \& Ziderman (2008), Poutvaara (2004), and Hillman (2015). Results are mixed, similarly to the worldwide practice of student lending where IC and traditional, fixed repayment schemes coexist with a wide variety of hybrid forms.

There are only few papers dealing with IC repayment in general and analyzing its potential extension to fields other than education. The first paper that mentioned the idea of IC schemes in relation of mortgage loans was published by Modigliani (1976). However, in Modigliani's model, the repayment obligation depended on the average income of the whole population rather than on the individual income of each borrower. Following the same logic, Simonovits (1992) proposed a special IC scheme to the 
Hungarian retail mortgage market after the crisis of the transition. Despite these early innovative ideas, IC schemes were realized only in student loan systems for many years, and issue of possible generalizations reappeared in the literature only as a consequence of the global crisis of 2007-2008. Chapman \& Hunter (2009) surveyed new ideas in the literature about potential areas where IC loans may be applied to: e.g. innovation financing, agricultural loans, parental leave and even public private partnerships. Stiglitz et al. (2014) also recommended to introduce IC schemes to new fields of retail lending, for example in case of unemployment, launching small enterprises, or any kinds of temporary financing problems. They consider IC loans as one of the most powerful policy tools against poverty and social exclusion. Stiglitz (2013) proved that income contingent loans can increase welfare in case of high uncertainty or other market failures like asymmetric information. Berlinger \& Walter (2015) proposed to introduce an income contingent repayment scheme for non-performing foreign-currency mortgage portfolios in Hungary.

When calculating expected maturities, repayment paths and expected losses, the usual approach in the literature is to run complex multivariable simulations which may lead to a "black box" effect discouraging policy makers to implement such schemes. The novelty of this paper is that we explore the basic characteristics of IC loans in a formal model in order to understand better its structure at an individual level. In the next sections, we provide closed formulas to describe stability, success and the shape of different debt paths. Our results help to understand better the special features of this unusual scheme which may contribute to its popularity and widespread application.

\section{The Model of Income Contingent Repayment}

In this part, we analyze the time evolution of the debt $(D)$, in line with the income $(I)$ and the repayment $(P)$ at an individual level within the framework of a discrete time model, where $\Delta t=1$ year, and values relate to the end of the given year. The loan is taken out in $t=0$, and right from $t=1$ the repayment is a fixed $(\alpha)$ proportion of the gross income of the actual year, where $1>\alpha>0$. The repayment is due until the debt is fully repaid $\left(D_{t}=0\right)$ or until the retirement of the borrower $(t=N)$. All variables are expressed in their nominal value. For the sake of simplicity, inflation, the real interest rate of the loan and the real income growth rate are supposed to be constant over time. According to our notation $r$ is for the interest rate factor (1+ nominal interest rate of the loan), and $w$ is for the income growth rate factor $(1+$ growth rate of the nominal gross personal income of a year).

As $P_{t}=\alpha \cdot I_{t}$ and $I_{t}=w^{t} \cdot I_{0}$, the absolute debt at the end of the $t$ th year $\left(D_{t}\right)$ is

$$
D_{t}=r \cdot D_{t-1}-\alpha \cdot w^{t} \cdot I_{0}
$$

and the solution to this difference equation is

$$
D_{t}=r^{t} \cdot D_{0}-\sum_{k=1}^{t} r^{t-k} \cdot \alpha \cdot w^{k} \cdot I_{0}
$$

Absolute debt in itself tells little about the debt burden; therefore, it is worth to compare this amount to the potential repayment in the given year, the $\alpha$ percent of actual income. We call this ratio as relative debt $(R)$ :

$$
R_{t}=\frac{D_{t}}{\alpha \cdot I_{t}}=\frac{D_{t}}{P_{t}}
$$


The numerator of $R$ is determined by the loan amount and the interest rate of the loan, while the denominator depends on the repayment rate $(\alpha)$ and the actual income, thus, it incorporates all relevant information. The value of $R$ changes year by year, and its process determines the basic characteristics of the debt path. Equations (1) and (2) can be expressed in terms of $R$ :

$$
\begin{gathered}
R_{t}=\frac{r}{w} R_{t-1}-1 \\
R_{t}=\left(\frac{r}{w}\right)^{t} \cdot R_{0}-\sum_{k=1}^{t}\left(\frac{r}{w}\right)^{-k}
\end{gathered}
$$

Thus, in this model $R$ depends solely on the initial relative debt $\left(R_{0}\right)$, and the ratio of $r / w$.

\section{Characteristics of the Debt Path: Stability, Success and Shape}

At a given level of $R_{0}$ we can define the lines which separate the points in the $r$-w plane (in the following analysis $r$ is on the $x$-axis, while $w$ is on the $y$-axis) in terms of stability, success and shape of the corresponding debt path.

Proposition 1. The "stability" line is given by $w=r$. Points located above this line represent stable $R$-paths, while points below it represent the instable ones. In case of the points right on the line there is no fix point.

Proof. It can be easily seen that the fix point of $R$ is

$$
R^{*}=\frac{w}{r-w}
$$

if $r \neq w$. If the ratio $R$ takes this value, it will not change any more. Using (3) and (5):

$$
R_{t}-R^{*}=\frac{r}{w}\left(R_{t-1}-R^{*}\right)
$$

Therefore, the distance to the fix point will change by $\frac{r}{w}$ over time. From this point of view, we can distinguish three cases:

1. In case of $\frac{r}{w}<1$ the difference from the fix point decreases over time, hence the equilibrium is stable. Given that the fix point is negative, and is positive, $R$ will converge to a negative value from upward.

2. In case of $\frac{r}{w}=1 R$ linearly converges to minus infinity over time; hence there is no fix point.

3. In case of $\frac{r}{w}>1$ the difference from the fix point increases over time, hence the equilibrium is instable. As the fix point is positive in this case, the system can start from three possible positions:

a) $R_{0}<\mathrm{R}^{*}: R$ will get farther from the fix point with an increasing speed, and its value converges to negative infinity.

b) $\quad R_{0}=\mathrm{R}^{*}: R$ does not change over time, however this is just a hypothetical scenario as any infinitesimal effect could easily move the system from this state.

c) $R_{0}>: R$ will get farther from the fix point with an increasing speed, and its value converges to positive infinity. 
We can conclude that in case of $r>w, R$ paths become instable, as they are diverging from their fix point over time.

Proposition 2. The "success" line (over infinite period) is given by $w=r \cdot \frac{R_{0}}{R_{0}+1}$. Points located above this line entail successful repayment, while points on and below the line represent those situations where full repayment is not possible.

Proof. Absolute debt $(D)$ becomes zero if and only if the relative debt $(R)$ becomes zero. As we could see at the proof of Proposition 1, in cases of 1., 2., and 3.a) the initially positive $R$ converges to a negative value (finite or infinite), thus, at a certain point it must become zero. At this point full repayment is reached. However, in case of 3.b) when the initial relative debt is just $\frac{w}{r-w}$, and in case of 3.c) when the relative debts is even higher, the $R$ ratio will never reach the zero level, hence the full repayment is not possible. It follows that successful and unsuccessful debt paths are separated by the line of $\quad \frac{}{r w}$ which can be easily transformed to $w=r \cdot \frac{R_{0}}{R_{0}+1}$.

Proposition 2 implies that successful repayment does not necessarily require that the income growth rate factor $(w)$ exceed the interest rate factor $(r)$.

Proposition 3. The "shape" line is given by $w=r \cdot R_{0}-R_{0}$. Points located on and above this line represent a monotonic decreasing absolute debt path, while points below the line represent those situations where absolute debt is increasing in the first years.

Proof. Based on (2) the change of the absolute debt is

$$
\Delta D_{t}=r^{t} \cdot D_{0}-\sum_{k=1}^{t} r^{t-k} \cdot w^{k} \cdot \alpha \cdot I_{0}-r^{t-1} \cdot D_{0}+\sum_{k=1}^{t-1} r^{t-1-k} \cdot w^{k} \cdot \alpha \cdot I_{0}
$$

which can be expressed as

$$
\Delta D_{t}=\frac{1}{r}\left((r-1) \cdot D_{t}-\alpha \cdot I_{t}\right)
$$

Using (4) it follows that the absolute debt in year $t$ is increasing if $R_{t-1}>\frac{w}{r-1}$; it does not change if $R_{t-1}=\frac{w}{r-1}$; and it is decreasing if $R_{t-1}<\frac{w}{r-1}$. Therefore, the absolute debt path can have three different shapes. If $R_{0}$ is greater than $\frac{w}{r-1}$, then $D$ is increasing in the first some years. Given that $r$ and $\alpha$ are constant, it follows from (8) that if $D$ grows faster than $I$, then $D$ keeps growing at an increasing rate, and full repayment will never be achieved. However, if $D$ is increasing, but its growth rate factor is less than $w$, then $D$ reaches its maximum within a finite time frame, and after this maximum point $D$ will decrease at an increasing rate. In more favorable cases, when $R_{0}$ equals or is less than $\frac{w}{r-1}, D$ follows a monotonic decreasing path. The "shape-line" comes from $R_{0}=\frac{w}{r-1}$.

Figure 1 depicts the position of stability, success and shape lines in case of an initial relative debt of 10 . 
Figure 1 | Stability, success and shape lines for infinite period $\left(R_{0}=10\right)$

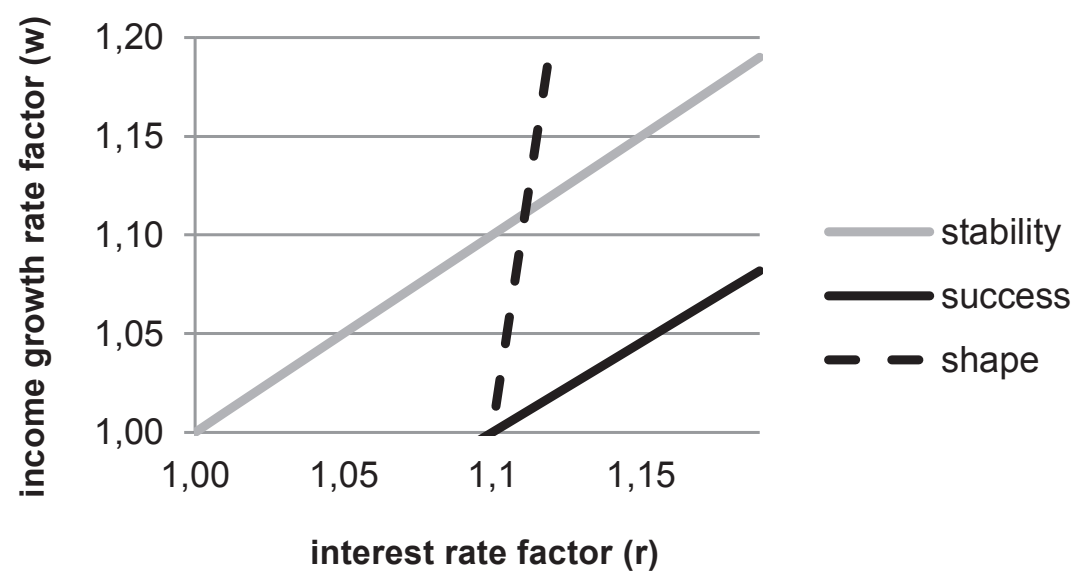

Source: authors

If $w>1$, then it can be easily seen that success and shape lines always cross each other at $w=1$ and success line lies always below the shape line. In this way, success and shape lines divide the plane into three subsections:

- Debt trap: on the success line and below we can found the unfavorable points representing debt paths which are monotonic increasing, hence, in this case it is impossible to reach full repayment.

- Humped shape: between the shape line and the success line we can find the points representing successful but humped shape debt paths, where absolute debt is increasing in the first years but later on it turns over and starts to decrease.

- Monotonic decreasing: on the shape line and above we can find the monotonic decreasing debt paths.

We note that monotonic decreasing and humped shaped paths can be stable or instable depending on their position relative to the stability line, while in a debt trap all paths are instable. Figure 2 illustrates the three different types of debt paths.

Figure 2 | Debt paths

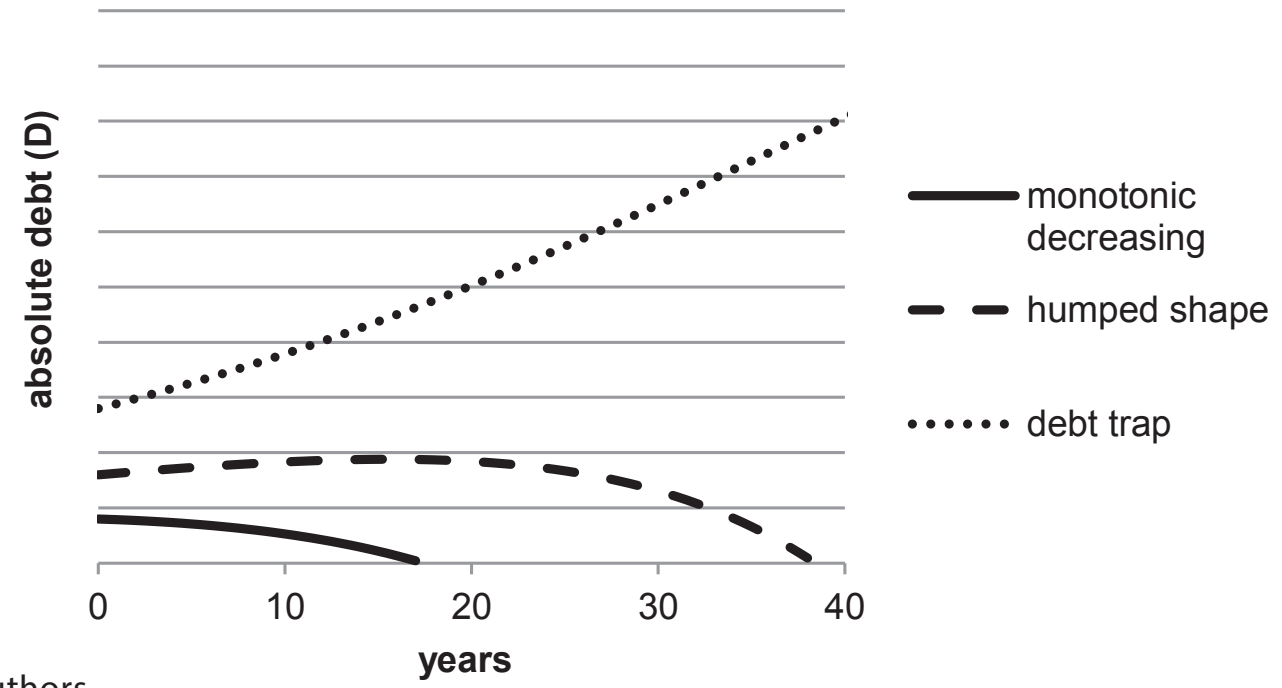

Source: authors 
It is notable that the income growth rate factor $(w)$ and the interest rate factor of the loan $(r)$ are present in the equations only in the form of $r / w$, therefore at a given level of $R_{0}$ the change in the inflation $(i)$ does not influence the position of the stability, the success and the shape lines, provided that $w$ and $r$ change simultaneously and proportionally. For example, if inflation rises, then the maturity of the loan does not change, but the nominal debts and the repayments increase and humped debt paths become even more humped which can be frightening for the borrowers, but fundamentally it does not make any difference, see Figure 3.

Figure 3 | The effect of inflation on the shape of the debt path $\left(R_{0}=10, r / w=0.99\right)$

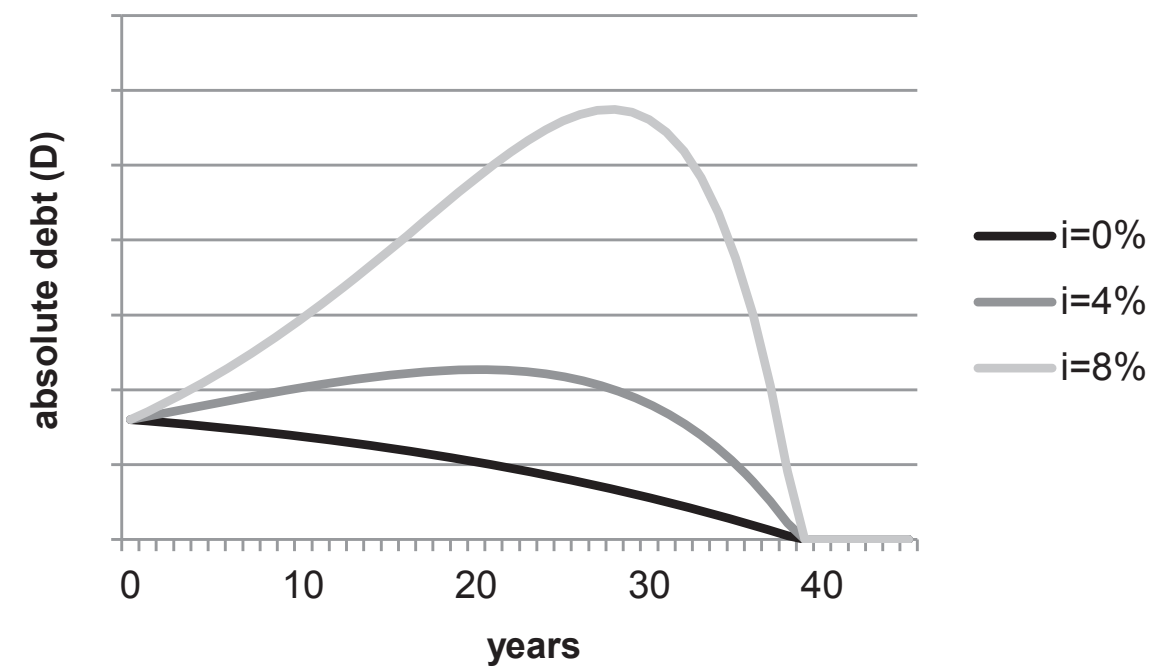

Source: authors

Until now, we considered an infinite repayment period. However, in practice the repayment period is finite (lasts until retirement or until the death of the borrower). If the maximum length of the repayment period is $N$, then the success line should be redefined.

Proposition 4. The "success" line over finite period is given by $R_{0}=\sum_{k=1}^{N}\left(\frac{w}{r}\right)^{k}$. Points located above this line represent successful repayment within $N$ years, while points on and below the line represent those situations where full repayment is not achieved.

Proof. Let us denote the year of reaching full repayment by $t^{*}$. By definition

$$
D_{t^{*}}=r^{t^{*}} \cdot D_{0}-\sum_{k=1}^{t^{*}} r^{t^{*}-k} \cdot w^{k} \cdot \alpha \cdot I_{0}=0
$$

hence

$$
R_{0}=\frac{D_{0}}{\alpha \cdot I_{0}}=\sum_{k=1}^{t^{*}}\left(\frac{w}{r}\right)^{k}
$$

If $N \geq t^{*}$, then the loan can be fully repaid until $t=N$, otherwise it is not possible, and the loan will be repaid only partly, hence $R_{0}=\frac{D_{0}}{\alpha \cdot I_{0}}=\sum_{k=1}^{t^{*}}\left(\frac{w}{r}\right)^{k}$ really separates successful and unsuccessful paths. 
Specifically, when $r=w$, then (10) reduces to $R_{0}=\frac{D_{0}}{\alpha \cdot I_{0}}=t^{*}$, meaning that in case the interest rate and the income growth rate are equal (so called golden path), the initial relative debt equals the length of the repayment period (in years). Equation (10) gives the equation of the success line only implicitly. Figure 4 shows the position of finite success lines with $N=40$ years and with $R=10$ or 20 relative to the infinite ones.

Figure 4 | Stability, success and shape lines for finite period ( $R=10$ or 20, $N=40$ years)
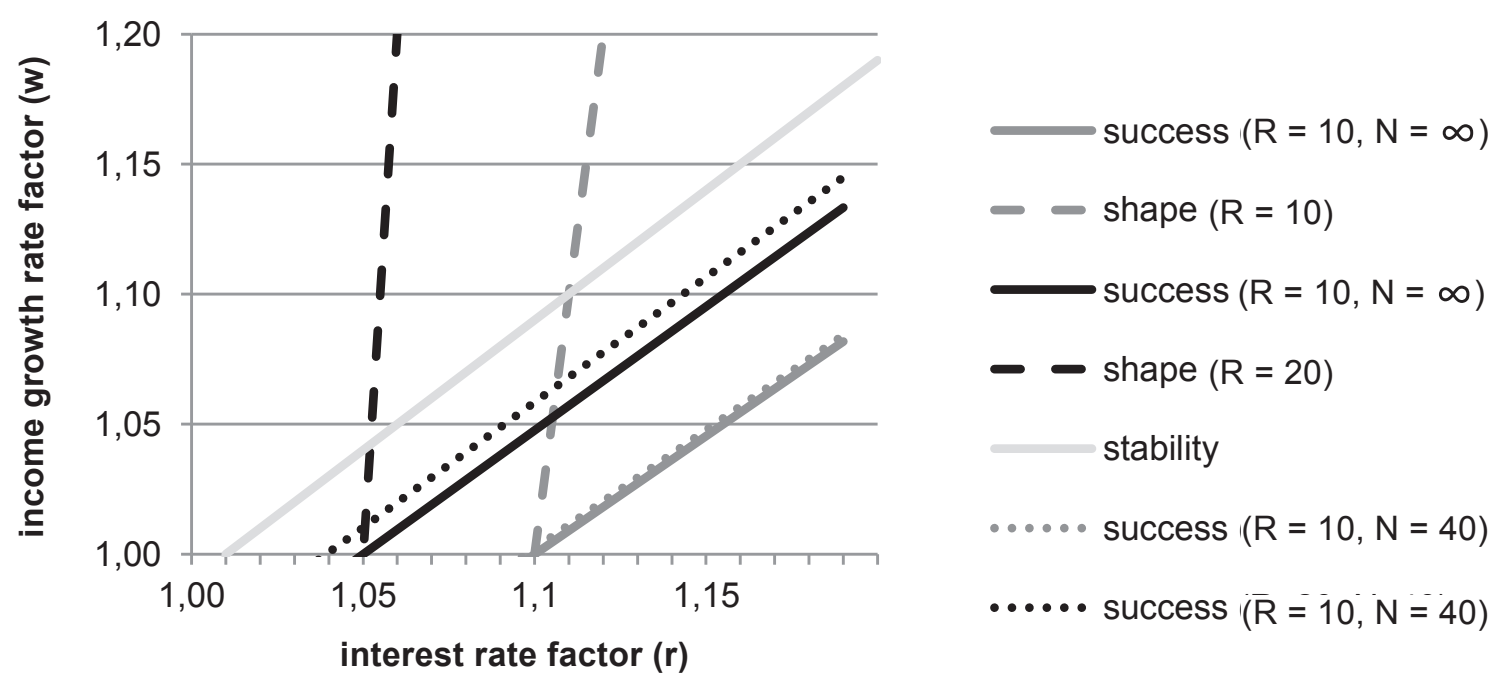

Source: authors

We can see that the switch from infinite to finite repayment period influences only the success line. A shorter repayment period lifts the success line to some extent. The difference between finite and infinite success lines is greater if $R$ is greater. In other words, the age of the borrower matters more when the relative debt is higher.

\section{Conclusions and Practical Implications}

In an income contingent scheme, the key variable is the relative debt $(R)$ which compares the actual debt to the repayment of one year. If the interest rate of the loan is equal to the income growth rate, then $R$ gives the expected maturity of the loan (in years), as well. In this model with constant rates, debt paths depend on the relationship between the initial value of the relative debt $\left(R_{0}\right)$, the interest rate factor of the loan $(r)$ and the growth rate factor of the gross income $(w)$.

The absolute debt $(D)$ may follow three different paths: unsuccessful monotonic increasing, successful but humped shaped and successful monotonic decreasing. The full repayment of the loan is only possible in the last two cases (monotonic decreasing and humped shaped). Over $N$ years the loan can be fully repaid if and only if $R_{0} \leq \sum_{k=1}^{N}\left(\frac{w}{r}\right)^{k}$. It means that $w, r$ and $N$ determine the maximum level of the relative debt which can be given out. Over an infinite period, this formula simplifies to $w \geq r \cdot \frac{R_{0}}{R_{0}+1}$. This allows also $w<r$. 
It may happen that the borrower gets into a "debt trap", meaning that he/she repays regularly as it is scheduled, but full repayment is never achieved. It can be due to the high loan amount, the high interest rate, the low initial income, the low income growth rate, the low repayment rate, the high age of the borrower or the combination of these factors. However, an increasing debt does not necessarily mean a "debt trap". If income grows faster than the debt, then the debt reaches its maximum in finite time, and beyond this point it starts to decrease sharply.

In most of the income contingent schemes, it is not possible to avoid these "humped" debt paths, because borrowers are heterogeneous in their debt, income and age, and most of them will typically belong to this intermediate group. If all borrowers were able to repay very quickly along monotonic pathways, then the potential in the income contingent scheme would not be exploited. It follows that good communication is essential, especially in the first years of the repayment period, helping the borrowers to understand that the income contingent scheme is inherently patient, and this is why humped debt paths are a very normal phenomenon.

For human resource managers, the main conclusion is that if an employee has an income contingent repayment obligation, then long-term career planning is much more important than usual. The employer should be aware that it is difficult to live with an increasing debt even if the employee can rationally understand that it is not likely to be a debt trap. Therefore, the compensation package should be carefully designed in order to avoid escalating nominal debts. Depending on the exact rules of the given student loan scheme, it may be worthwhile to consider the timing of parental leave, the early repayment of the loan, the takeover of the loan repayment by the employer, or possibly the speed-up of the career of the freshly graduates.

When it is about extending the scope of income contingent loans to other areas of retail lending (innovation financing, rural small businesses, extension of parental leave, unemployment aid etc.), financial engineers should also calculate with the burden of increasing debts not only from the borrower's but also from the lender's point of view. The aggregate loan exposure tends to grow fast in the first years with all its consequences on risk management, financing strategy and administration. The lender must also find the ways to manage the cash-flow risk following from the fact that loan repayments are not fixed but are the function of stochastic individual incomes which can be difficult to forecast and monitor. Moreover, in many cases maturities will be very long, lasting several decades (e.g. until retirement), and borrowers may be tempted to hide their income or to escape. To sum it up this innovative new scheme requires innovative new approaches in many management areas at financial institutions, as well.

\section{References}

Barr, N. (1998). Higher Education in Australia and Britain: What Lessons? The Australian Economic Review, 31(2), 179-198.

Barr, N. (2001). The Welfare State as Piggy Bank. Oxford: Oxford University Press.

Berlinger, E. \& Walter, G. (2015). Income contingent repayment scheme for non-performing mortgage loans in Hungary. Acta Oeconomica, 65(S1), 123-147.

Chapman, B. (1997). Conceptual issues and the Australian Experience with income-contingent charges for higher education. Economic Journal, 107(442), 738-751. 
Chapman, B. \& Hunter, B. H. (2009). Exploring Creative Applications of Income Contingent Loans, Australian Journal of Labour Economics, 12(2), 133-144.

Friedman, M. (1962). Capitalism and Freedom. Chicago: University of Chicago Press.

Harding, A. (1995). Financing higher education: an assessment of income-contingent loan options and repayment patterns over the life cycle. Education Economics, 3(2), 173-203.

Hillman, N. W. (2015). College on Credit: A Multilevel Analysis of Student Loan Default. The Review of Higher Education, 37(2), 169-195.

Modigliani, F. (1976). Some economic policy implications of indexing of financial assets with special reference to mortgages. In: Monti, M. (Ed.), The New Inflation and Monetary Policy, London and Basington, Macmillan, 90-116.

Palacios, M. (2003). Options for financing lifelong learning (Vol. 2994). World Bank Publications.

Poutvaara, P. (2004). Educating Europe: Should Public Education be Financed with Graduate Taxes or Income-contingent Loans? CESifo Economic Studies, 50(4), 663-684.

Shen, H., \& Ziderman, A. (2009). Student loans repayment and recovery: international comparisons. Higher education, 57(3), 315-333.

Simonovits, A. (1992). Mathematical analysis of indexed loans and expectations. Hungarian Economic Review, 3, 262-278.

Stiglitz, J. E. \& Jun, J. (2013). Optimal provision of loans and insurance against unemployment from lifetime perspective. NBER Working Paper 19064.

Stiglitz, J. E., Higgins, T., \& Chapman, B. (2014). Income Contingent Loans: Theory, Practice and Prospects. Palgrave Macmillan Limited.

\section{Authors}

Dr. Edina Berlinger

Associate Professor, Head of Department of Finance

Corvinus University of Budapest

H-1093 Budapest, Fővám tér 8.

edina.berlinger@uni-corvinus.hu

\section{Dr. György Walter}

Associate Professor

Corvinus University of Budapest

H-1093 Budapest, Fővám tér 8.

gyorgy.walter@uni-corvinus.hu 